\title{
Investigation on the Effects of Exchanged Power and Electrode Properties on Micro EDM Drilling of Stainless Steel
}

\author{
Gianluca D’Urso, Chiara Ravasio \\ University of Bergamo - DIGIP, Viale Marconi 5, 24044 Dalmine (BG) - Italy. Email: gianluca.d-urso@unibg.it, \\ chiara.ravasio@unibg.it
}

\begin{abstract}
Aim of this research is to study how the exchanged power and the electrode material and diameter affect the performance of micro EDM drilling of stainless steel. Copper and tungsten carbide electrodes, with two different diameters, were taken into account. Different values of the exchanged power were obtained by varying the main electrical parameters, namely peak current, voltage and energy level. A dedicated acquisition system for the measurement of effective electrical parameters during the drilling process was implemented. The considered process parameters and the electrode properties, in terms of both material and diameter, resulted to have influence on the drilling performance. Finally, both a linear and non-linear regression approaches were set up to obtain predictive equations about machining time and electrode wear.
\end{abstract}

Keywords: micro-EDM, micro-drilling, process parameters, copper electrode, tungsten carbide electrode, stainless steel.

\section{Introduction}

The need for products containing micro-features has shown a noticeable and continuous evolution in many fields and, within the different types of micro-feature, products containing micro-holes has shown remarkable growth in some industrial sectors [1-3]. For example, micro holes are widely requested in the production of medical and optical devices, turbine blades, cooling channels, diesel fuel injection nozzles [4,5]. Among the nonconventional technologies, micro electro-discharge machining $(\mathrm{EDM})$ is one of the most performing techniques capable of machining difficult to cut materials and to achieve, at the same time, the dimensional and geometrical performances usually requested by micro-scale components [6]. The main applications of micro-EDM technology are micro-milling, for the realization of complex 3D shapes, and micro-drilling for the realization of through and blind micro holes. A typical application of micro-EDM drilling is the realization of high aspect ratio micro holes used in fuel injectors; in this case microEDM can be considered the most appropriate technology since it ensures good circularity and absence of burrs on the hole edges.

EDM is a manufacturing technology based on rapid electric spark discharges between workpiece and electrode immersed in a dielectric fluid. The sparks cause the melting and the vaporizing of the material that is rapidly re-solidified and removed from the machining area by the dielectric flushing. With micro-EDM it is possible to machine any conductive material regardless of its hardness and strength, since the tool and the workpiece are always separated by a gap called sparking gap. Thanks to this property, no residual stresses or deformations are left on the workpiece [7]. Besides the numerous advantages of micro-EDM, the main drawbacks are represented by the low material removal rate, if compared with conventional or others non-conventional machining technologies like laser, and the considerable electrode wear, that is an unavoidable aspect of micro-EDM due to the electric sparks that involve the electrode as well.
Several electrical parameters have to be set up for the machining such as voltage, current, pulse duration, sparking gap and frequency. These parameters have effects on the erosion process in terms of tool wear ratio (TWR) and material removal rate (MRR) [8]; at the same time they can affect the properties of the machined workpiece in terms of surface finishing, dimensional and geometrical accuracy [9-11]. For example, during the execution of a deep hole, the debris accumulation at the bottom of the hole may cause abnormal discharges, resulting in machining speed reduction and possible geometrical and dimensional alteration [12]. As a matter of fact, the electrode wear can be minimized with an appropriate selection of the process parameters, that are demonstrated to have a considerable influence on the process performance and on the geometrical characteristics of the micro holes. Many researchers investigated these aspects, for example, in [13] a particular emphasis was given to the selection of the proper manufacturing conditions, that was carried out with a DOE approach in order to reduce the total amount of tests repetitions. It was demonstrated that the most significant factors were the peak current and the pulse time, while the duty cycle was negligible at the considered confidence level. Similar results were obtained in [14]. In [15] an overview about EDM process parameters and a modelling of their effects on performance indicators is presented.

Besides the process parameters, also the thermoelectrical characteristics of the electrode materials are of primary importance in terms of process performance; several studies investigated this aspect taking into account copper, brass and tungsten carbide electrodes [16]. In [17] a comparison between copper and brass electrodes was carried out in machining aluminium and mild steel. Between the two electrode materials, brass was characterized by the highest electrode wear, when machining steel, while the highest material removal rate was obtained when machining aluminium with brass electrode. In [18] a fine finishing EDM of tungsten carbide workpiece was carried out with different electrodes $(\mathrm{CuW}, \mathrm{AgW}$, W). It was demonstrated that copper based electrodes 
$(\mathrm{CuW})$ achieve the highest MRR followed by $\mathrm{AgW}$ and in the case of electrode wear, the $\mathrm{W}$ electrode has the lowest wear followed by $\mathrm{CuW}$ and $\mathrm{AgW}$. In [19] the performance of different $\mathrm{Cr} / \mathrm{Cu}$ based electrodes was investigated and basing on the thermal characteristics of these materials, their wear and corrosion resistance were evaluated. The best mixing ratios and condition for the realization of these electrodes were also identified and the process performance were finally optimized.

From the workpiece point of view, the effect of the process parameters on the surface integrity of the workpiece itself using $\mathrm{CuW}$ electrodes was studied in [20]. The influence of the workpiece hardness on the machining performance of EDM carried out with electrolytic copper was investigated in [21]. The results showed that the workpiece hardness has effect on both MRR and workpiece surface roughness.

Aim of this paper is to study how the exchanged power and the electrode material and diameter affect the performance of micro EDM drilling of stainless steel. In particular, copper and tungsten carbide electrodes having diameters equal to 150 and $300 \mu \mathrm{m}$ were taken into account. Three process parameters (peak current, voltage and energy level) were varied to obtain different values of exchanged power. A dedicated acquisition system was implemented in order to collect reliable information about the effective exchanged power between workpiece and electrode. Finally, two predictive models for the forecast of machining time and electrode wear as a function of exchanged power, electrode material and diameter were proposed.

\section{Experimental set up}

The experimental campaign was carried out with a Sarix SX 200 micro-EDM machine with tubular tungsten carbide (TC) and copper $(\mathrm{Cu})$ electrodes. For each electrode material, the experiments were performed using electrodes having external diameter equal to 300 and 150 micrometer and internal diameter equal to 120 and 60 micrometer, respectively. The drilling tests were carried out on 316L stainless steel sheets having thickness equal to $1 \mathrm{~mm}$. Kerosene dielectric oil was used and it was adduced to the machining zone with a pressure of 20 bar. A full factorial DOE approach was adopted: two process parameters (namely, peak current - I and voltage - V) were varied on three levels, codified as "low (L)", "medium (M)" and "high (H)". The Sarix energy parameter was varied on two levels, codified as 365 (high) and 206 (low). Five repetitions for every experimental conditions were executed, so resulting in 90 through micro holes for each electrode material and diameter (total amount of 360 through micro holes). The selection of the process parameters was done based on the results of the preliminary tests, considering tool wear and machining time minimization. Table 1 shows the varied and the fixed parameters used for both tungsten carbide and copper electrodes.

Tab. 1 Varied and fixed process parameters

\begin{tabular}{|c|c|c|c|c|c|c|c|c|c|c|c|c|c|}
\hline \multicolumn{8}{|c|}{ Varied } & \multicolumn{6}{|c|}{ Fixed } \\
\hline $\begin{array}{c}\text { Diameter } \\
{[\mu \mathrm{m}]}\end{array}$ & \multicolumn{2}{|c|}{$\begin{array}{c}\text { Energy level } \\
{[-]}\end{array}$} & \multicolumn{2}{|c|}{ I [-] } & \multicolumn{3}{|c|}{$\mathrm{V}[\mathrm{V}]$} & $\begin{array}{c}\text { Frequency } \\
{[\mathrm{kHz}]}\end{array}$ & $\begin{array}{c}\mathrm{T}_{\text {on }} \\
{[\mu \mathrm{s}]}\end{array}$ & $\begin{array}{l}\text { Gap } \\
{[\%]}\end{array}$ & $\begin{array}{c}\text { Gain } \\
{[-]}\end{array}$ & $\begin{array}{c}\text { Reg. } \\
{[-]}\end{array}$ & $\begin{array}{c}\text { Polarity } \\
{[-]}\end{array}$ \\
\hline \multirow{2}{*}{300} & 206 & 10 & 35 & 50 & 80 & 110 & 140 & \multirow{4}{*}{120} & \multirow{4}{*}{5} & \multirow{4}{*}{60} & \multirow{4}{*}{100} & \multirow{4}{*}{ 03_01 } & \multirow{4}{*}{ neg } \\
\hline & 365 & 40 & 60 & 80 & 80 & 100 & 120 & & & & & & \\
\hline \multirow{2}{*}{150} & 206 & 15 & 30 & 50 & 80 & 110 & 140 & & & & & & \\
\hline & 365 & 20 & 40 & 60 & 70 & 95 & 110 & & & & & & \\
\hline
\end{tabular}

The measurement of the tool wear after the execution of each hole was made in a referential point on the workpiece through an electrode touch executed before and after the drilling operation. Then, the electrode was cut using a wire EDM unit in order to reset the geometrical characteristics for the next hole. A ceramic electrode guide was used for the 150 micrometer electrode to avoid some possible tool bending effects. An automatic drilling program was implemented for this purpose.

\subsection{Electrical signal acquisition system}

A signal acquisition system was implemented with the purpose of finding an actual relation between machine input and output. Figure 1 shows an overall representation of the acquisition system (left) and the data acquisition process (right). Two electronics modules were developed for monitoring the electrode voltage on the high side and the discharge current on the low side respectively. By providing a bipolar supply the system is able to monitor the machining process even at inverted polarity. Both the modules provide large bandwidth ( $\mathrm{DC}<\mathrm{BW}<10 \mathrm{MHz}$ ) in order to preserve the microsecond-based structure of the EDM process and suitable gain in order to enter the scope with signals in the order of few volts. In particular, the voltage sensing is based on a high value resistor divider, in order to not affect the machine parameters. The obtained low voltage from the divider is successively amplified and buffered, providing the capability at the output to drive a $50 \mathrm{Ohm}$ load on a coaxial cable. As concerns the current monitor module, the current is sensed at machine low side in order to not use high voltage components; the current drawn from ground passes through a high-power, $10 \mathrm{mOhm}$ resistor. The voltage drop across this resistor is then differentially amplified and buffered for a $50 \mathrm{Ohm}$ matching on a coaxial cable. The electronic modules were mounted on the EDM machine close to the measurement points. 


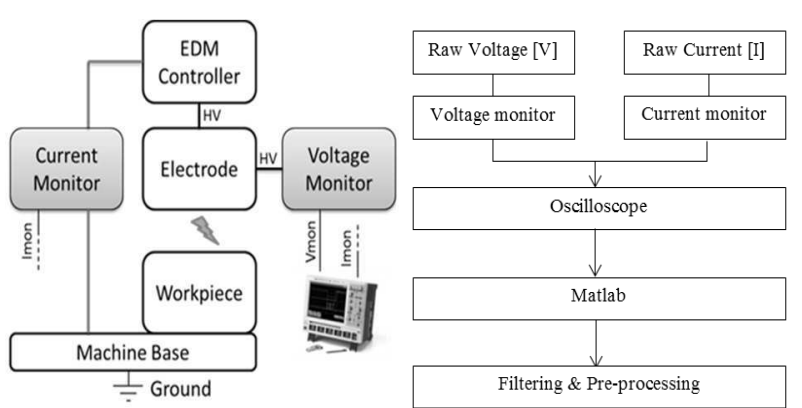

Fig. 1 Block diagram of the data acquisition system (left) and scheme of the data acquisition process (right)

BNC coaxial cables were finally connected to a Teledyne Le Croy Wavesurfer oscilloscope, programmed to perform simultaneous acquisitions of both voltage and current monitor at $1000 \mathrm{MS} / \mathrm{s}$. The acquisition process was automated with the use of a Matlab program and the data were fetched in regular intervals of time from the oscilloscope and saved as Matlab figure files. A specially designed script that iterates over all the data files and computes values such as energy per spark, peak current, peak voltage and number of sparks per second contributed to the analysis of the electrical graphs. A proper data filtering and a system to remove the data noise were also implemented.

In order to carry out an effective data filtering it is necessary to consider that the sparks are very short in duration and can be confused with simple noise by a filtering algorithm. As a matter of fact, the frequency band of the noise and the sparks are sufficiently different to allow an effective filtering procedure. Once the filtered peak current and voltage data were created, the power data $(\mathrm{P}(\mathrm{t}))$ was calculated through the multiplication of I and $\mathrm{V}$ data. The beginning of every spark is characterized by a sudden decrease of the voltage level and it is accompanied by an increase in the current value, in conformity with literature [22]. Based on the previous observation it is possible to state that a spark happens when voltage is below a certain level (Vthreshold) and current is above a certain level (Istart). When a spark ends, a spark is currently ongoing and the current is below a certain level (Iend). The choice of the three parameters, Vtreshold, Istart and Iend is crucial since the function able to detect the sparks needs to return the correct number of sparks. At the same time, the function needs to make the sparks comparable to themselves and achieve a certain level of consistency. Moreover, some information about the main process parameters need to be collected, such as the correct number of sparks and the number of detected sparks that maximize their energy. For each set of parameters used for the experimental campaign, a file was selected and the number of sparks was counted by means of an algorithm able to detect the beginning and the end of each spark. Once the effective number of sparks is known, it is possible to use that information as a constraint in the optimization process allowing the algorithm to find the values of Vtreshold, Istart and Iend that maximize the energy of all sparks. Using this solution, it was possible to compute all the most important parameters such as total number of sparks, average peak current, average peak voltage, number of sparks per second, average energy transferred per spark, average energy transferred per second.

\subsection{Geometrical characterization and evaluation of the process performance}

The geometrical characteristics of the micro holes were evaluated taking into account two different indicators, namely the Diametrical Overcut (DOC) and the Taper Rate (TR). The diameter was measured at both the top and the bottom of each hole through an optical measuring microscope at the magnification of $100 \mathrm{X}$. The DOC is calculated as the difference between the top diameter $\left(D_{\text {top }}\right)$ of the hole and the nominal external electrode diameter $\left(D_{\text {ext }}\right)$. The TR indicator is calculated as the difference between the top and bottom ( $\left.\mathrm{D}_{\text {bottom }}\right)$ hole diameters divided by the sheet thickness (h).

Two indicators were used to evaluate the process performance of micro-drilling. The first one is the MRR which is calculated as the material removed from the workpiece $\left(\mathrm{MR}_{\mathrm{wp}}\right)$ divided by the machining time $(\mathrm{t})$, as follows:

$$
M R R=\frac{M R_{w p}}{t}
$$

The material removed from the workpiece is calculated as the volume of the frustum of cone having dimensions equal to the hole top diameter and the hole bottom diameter, as reported below:

$$
M R_{w p}=\frac{\pi h\left(D_{t o p}^{2}+D_{t o p} \cdot D_{\text {bottom }}+D_{\text {bottom }}^{2}\right)}{12}
$$

As regards the TWR, it is calculated as the material removed from the tool $\left(\mathrm{MR}_{\text {tool }}\right)$ divided by the material removed from the workpiece, as follows:

$$
T W R=\frac{M R_{t o o l}}{M R_{w p}}
$$

where the material removed from the tool is calculated as the volume of the tubular electrode:

$$
M R_{\text {tool }}=\pi \cdot w \cdot \frac{\left(D_{\text {ext }}^{2}-D_{\text {int }}^{2}\right)}{4}
$$

\section{Analysis of the results}

\subsection{Analysis of variance}

The analysis of variance (ANOVA) was executed on the collected data evaluate the influence of the different process parameters on the final output expressed as machining time (t), electrode wear (w), MRR, TWR, DOC and TR indicators. Table 2 shows the p-values for all the indicators for the 300 micrometer electrode. The only factor for which all the p-values are lower than the cutoff limit (set equal to 5\%) is the electrode material (Mat). The other factors and their interactions show in several cases low p-values. Similar results were obtained for the 150 micrometer electrode. 
Tab. 2 Analysis of variance p-values for $300 \mu \mathrm{m}$ electrodes

\begin{tabular}{lcccccc}
\hline & $\mathrm{t}$ & $\mathrm{w}$ & $\mathrm{DOC}$ & $\mathrm{TR}$ & $\mathrm{MRR}$ & $\mathrm{TWR}$ \\
\hline $\mathrm{I}$ & 0.166 & 0.536 & 0.209 & 0.835 & $\mathbf{0 . 0 0 0}$ & 0.182 \\
V & $\mathbf{0 . 0 0 0}$ & $\mathbf{0 . 0 1 1}$ & 0.433 & 0.474 & $\mathbf{0 . 0 0 0}$ & $\mathbf{0 . 0 0 1}$ \\
E & $\mathbf{0 . 0 0 0}$ & $\mathbf{0 . 0 0 0}$ & $\mathbf{0 . 0 1 2}$ & 0.072 & $\mathbf{0 . 0 0 0}$ & $\mathbf{0 . 0 1 1}$ \\
Mat & $\mathbf{0 . 0 0 0}$ & $\mathbf{0 . 0 0 0}$ & $\mathbf{0 . 0 0 0}$ & $\mathbf{0 . 0 0 1}$ & $\mathbf{0 . 0 0 0}$ & $\mathbf{0 . 0 0 0}$ \\
I*V & $\mathbf{0 . 0 0 7}$ & 0.851 & 0.092 & 0.257 & 0.500 & 0.746 \\
I*E & 0.160 & $\mathbf{0 . 0 0 0}$ & 0.486 & 0.684 & $\mathbf{0 . 0 1 3}$ & $\mathbf{0 . 0 0 0}$ \\
I*Mat & $\mathbf{0 . 0 0 1}$ & $\mathbf{0 . 0 0 0}$ & 0.130 & 0.146 & 0.217 & $\mathbf{0 . 0 0 0}$ \\
V*E & $\mathbf{0 . 0 0 0}$ & $\mathbf{0 . 0 0 0}$ & 0.136 & 0.257 & $\mathbf{0 . 0 3 0}$ & $\mathbf{0 . 0 0 0}$ \\
V*Mat & $\mathbf{0 . 0 1 8}$ & $\mathbf{0 . 0 0 0}$ & 0.231 & 0.341 & 0.161 & $\mathbf{0 . 0 0 0}$ \\
E*Mat & $\mathbf{0 . 0 0 0}$ & $\mathbf{0 . 0 0 0}$ & $\mathbf{0 . 0 0 0}$ & 0.318 & 0.482 & $\mathbf{0 . 0 0 0}$ \\
I*V*E & $\mathbf{0 . 0 1 0}$ & 0.220 & $\mathbf{0 . 0 1 0}$ & 0.165 & 0.850 & $\mathbf{0 . 0 4 3}$ \\
I*V*Mat & $\mathbf{0 . 0 0 1}$ & 0.905 & $\mathbf{0 . 0 5 0}$ & 0.123 & 0.684 & 0.562 \\
I*E*Mat & $\mathbf{0 . 0 0 0}$ & 0.070 & 0.270 & 0.247 & $\mathbf{0 . 0 0 3}$ & $\mathbf{0 . 0 2 5}$ \\
V*E*Mat & $\mathbf{0 . 0 0 0}$ & $\mathbf{0 . 0 0 1}$ & 0.847 & 0.909 & $\mathbf{0 . 0 0 0}$ & $\mathbf{0 . 0 0 1}$ \\
I*V*E*Mat & $\mathbf{0 . 0 0 1}$ & 0.805 & $\mathbf{0 . 0 1 3}$ & 0.109 & 0.460 & 0.414 \\
\hline
\end{tabular}

In order to evaluate possible interactions between the factors, the interaction plots were evaluated for both 300 and 150 micrometer electrodes. For example, figure 2 shows the wear indicator results obtained for the 300 micrometer electrode. A considerable interaction can be observed between the electrode material and the energy level. Moreover, it is possible to notice a significant interaction for the energy level, the peak current and the voltage. This results are confirmed for the geometrical characteristics. Similar results have been obtained for the 150 micrometer electrode.

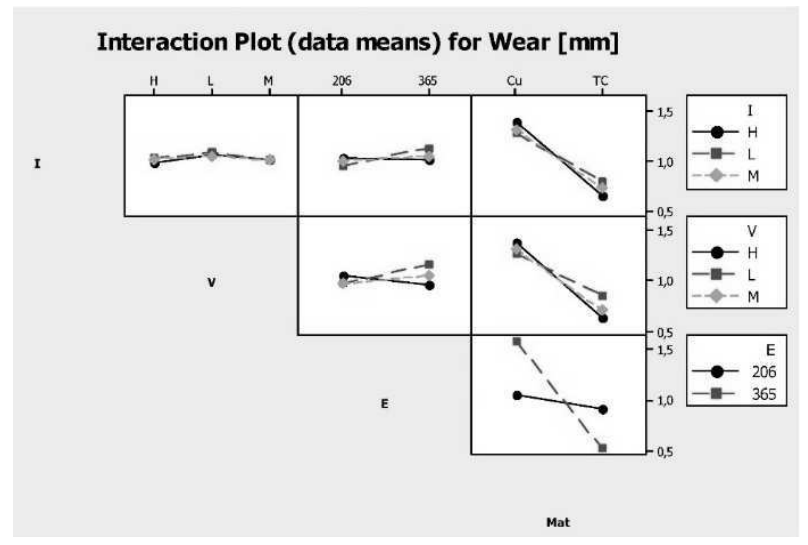

Fig. 2 Interaction plot for wear as a function of $I, V, E$ and electrode material, $d 300 \mu \mathrm{m}$

\subsection{Effects of the exchanged power}

In order to investigate the combined influence of current, voltage and energy level on the final result, the calculated exchanged power was taken into account. This power, that is exchanged between the tool and the workpiece, can be calculated as follows:

$$
P(t)=I(t) \cdot V(t)
$$

where $\mathrm{P}[\mathrm{W}]$ represents the exchanged power, I [A] the peak current and $\mathrm{V}[\mathrm{V}]$ the voltage. The acquisition system measurements allowed to collect information about the exchanged power, by knowing the number of sparks per second and the energy per spark. For example, Figure 3 shows the exchanged power calculated for $\mathrm{TC}$ and $\mathrm{Cu}$ electrodes, diameter 300 micrometer and energy level 365 , as a function of the level of peak current and voltage (for each bar, the first letter represents the peak current level, while the second one represents the voltage level). The use of copper electrode, having a lower electrical resistivity, results in a higher exchanged power with respect to tungsten carbide, even though the experiments were executed with the same process parameters. For both lower energy index and lower diameter, the calculated exchanged power is reduced and the same trend is verified.

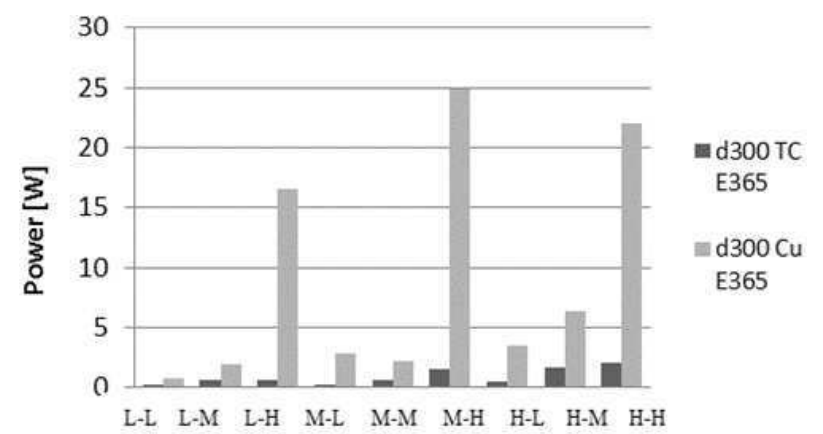

Process Parameters' combination

Fig. 3 Exchanged power for TC and Cu electrode, $d 300$ $\mu \mathrm{m}, \mathrm{E365}$

MRR as a function of the exchanged power shows in all the conditions (material and diameter electrode) an increasing trend with a satisfactory correlation coefficient (Figure 4). 

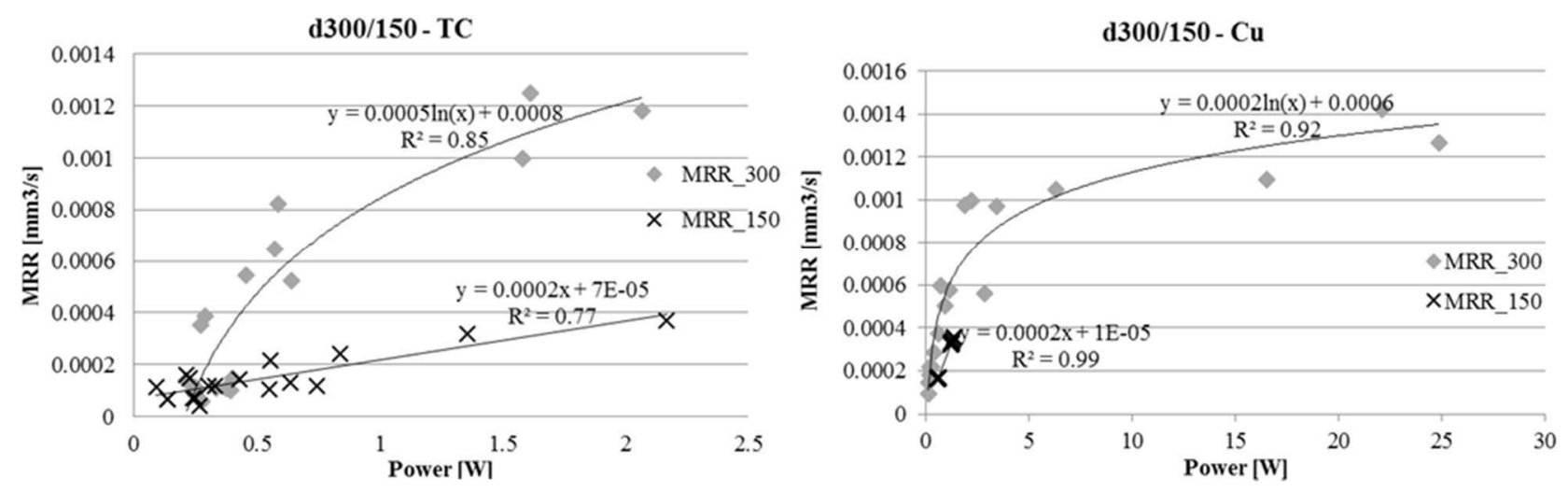

Fig. 4 MRR as a function of the exchanged power for tungsten carbide (left) and copper (right) electrode

It can be noted the difference of $\mathrm{x}$-axis between the two graphs; in fact, using copper electrode having a diameter equal to $300 \mu \mathrm{m}$, the maximum value of the calculated exchanged power is around ten times higher than the other experimental conditions. The reduction of diameter electrode results in a lower MRR for both tungsten carbide and copper electrode. The comparison between the

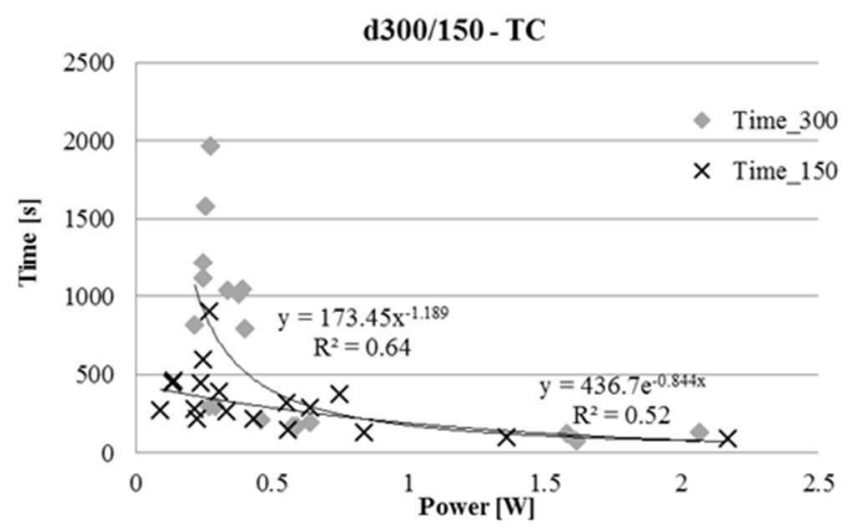

two electrode materials highlights how copper permits to obtain higher removal speeds than tungsten carbide thanks to its electrical properties, as already reported in [23]. Machining time graphs (Figure 5) show that, generally, the increase of discharged power improves the drilling time; moreover the drilling time is influenced by both the diameter and the electrode diameter.

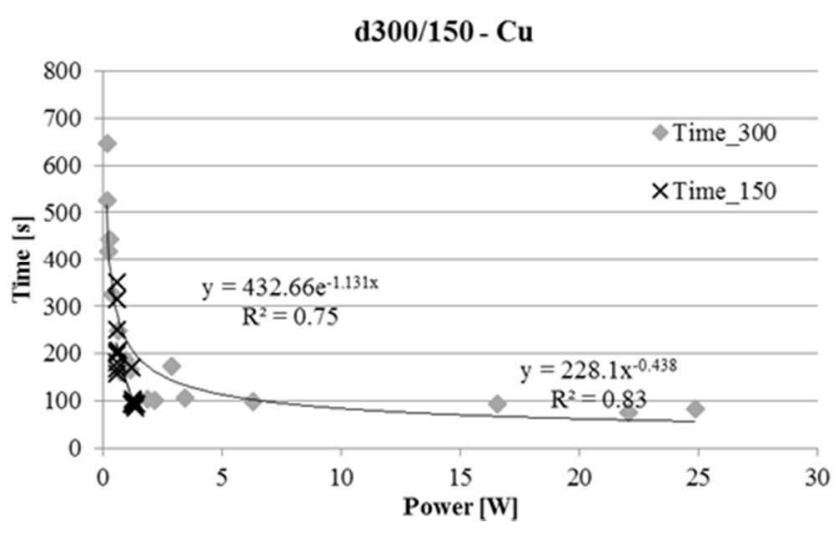

Fig. 5 Machining time as a function of the exchanged power for tungsten carbide (left) and copper (right) electrode

d300/150 - TC

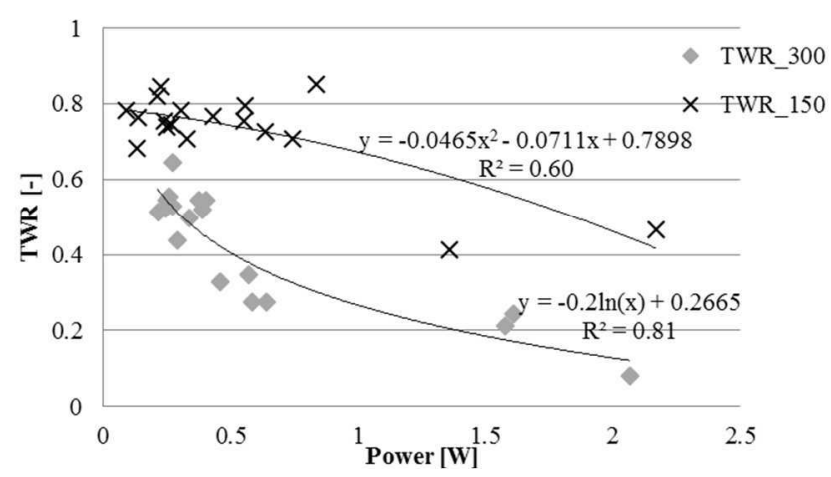

d300/150 - Cu

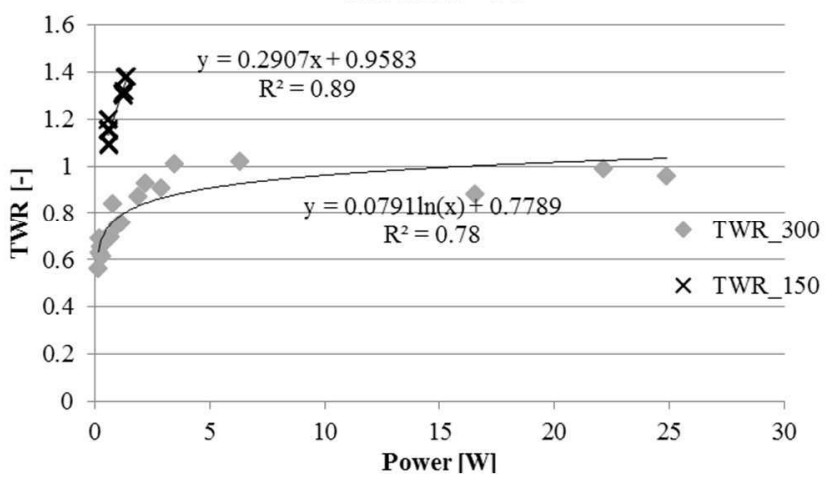

Fig. 6 TWR as a function of the exchanged power for tungsten carbide (left) and copper (right) electrode

Figures 6 and 7 report TWR and electrode wear trend as a function of the discharged power for both diameter and material electrode. TWR and electrode wear are always higher for the smallest diameter electrode while the comparison between the two electrode material shows a different behavior: using tungsten carbide electrode, TWR and wear have a decreasing trend as a function of the power discharged; the situation is opposite when copper electrode is used. This effect can be related to the higher electrical conductivity and lower melting point of copper with respect to TC. Tungsten carbide electrode permits to optimize the process performance in terms of both MRR and TWR through the increasing of the discharged power. 

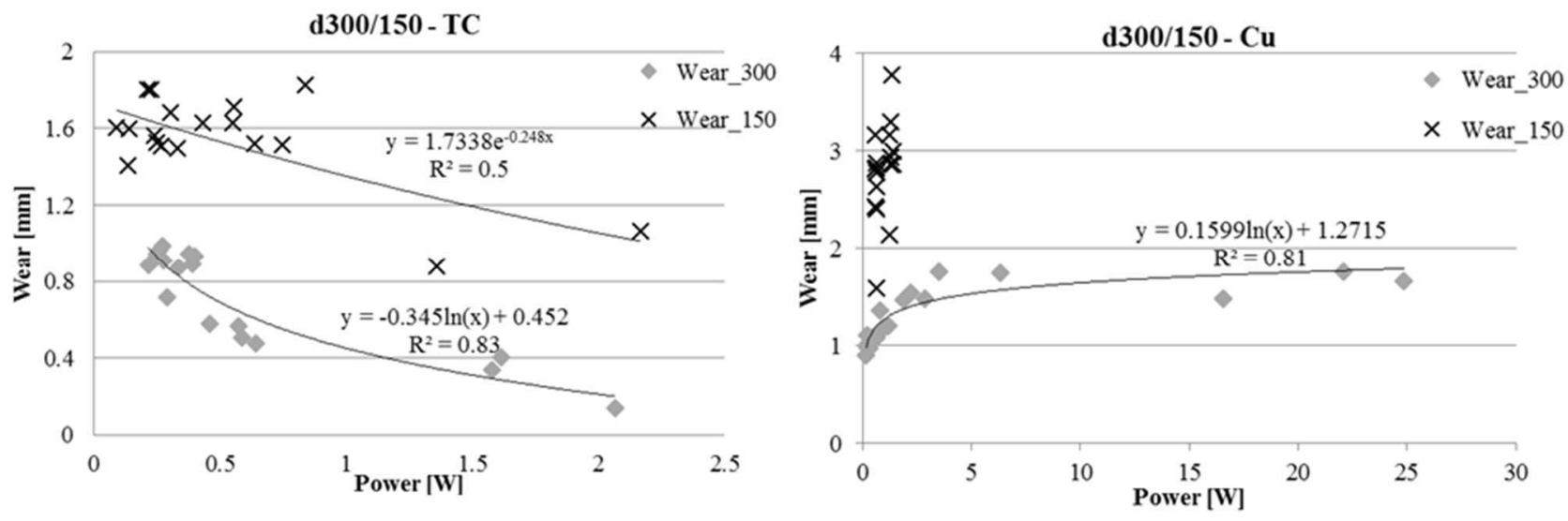

Fig. 7 Electrode wear as a function of the exchanged power for tungsten carbide (left) and copper (right) electrode

As regard the geometrical characteristics of micro holes, Figure 8 shows DOC as a function of discharged power. Using tungsten carbide electrode for both diameters, no trends were found: except for some particular conditions, DOC assumes a value in the range of 60-70 $\mu \mathrm{m}$. Using $300 \mu \mathrm{m}$ copper electrodes, DOC increases

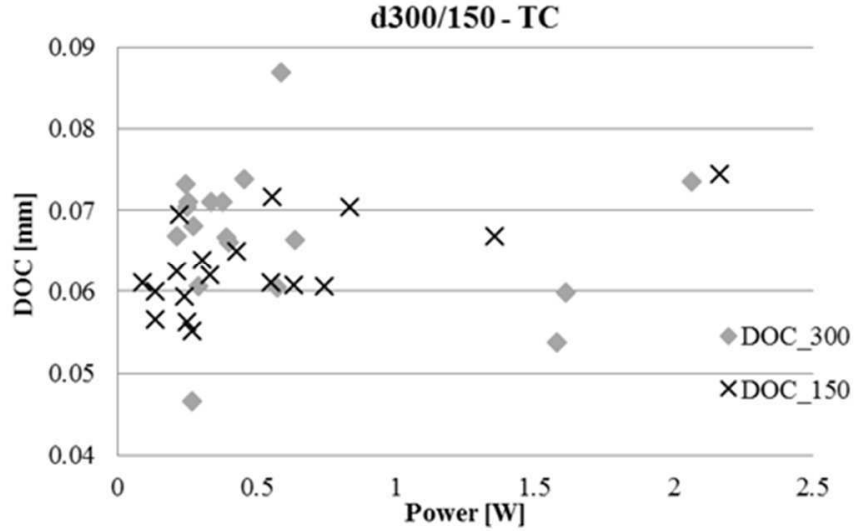

Fig. 8 DOC as a function of the exchanged power for tungsten carbide (left) and copper (right) electrode

Finally, for TR no particular trend was found for both diameters and electrode materials but, in general, copper electrode permits to have holes with lower conicity than using tungsten carbide. The higher erosion speed related to the use of copper electrode and then the lower permanence time of the tool in the hole is the reason of lower taper rate.

\section{Predictive models}

Both linear and non-linear regression models for the forecast of machining time and electrode wear were defined and their prediction capabilities were evaluated. WEKA data analysis software was used for this purpose. The "linear" approach is a simple regression analysis while the "non-linear" one, in other words a "model tree" method, is a solution that deals with each branch of the tree using a suitable linear regression equation.

For both models, a 10 fold cross validation approach was used, meaning that the data set is divided in ten parts, with a logarithmic law when the discharged power increases; for $150 \mu \mathrm{m}$ diameter the trend is opposite but the difference between the maximum and the minimum is very small, in order of some microns. The correlation index $\left(\mathrm{R}^{2}\right)$ of the regression curves shown in Figures 5-8 does not always get a satisfactory value.

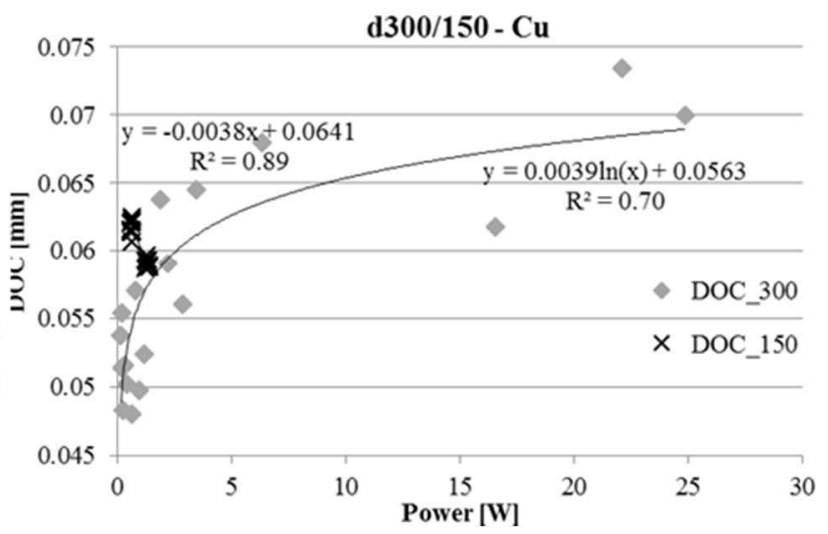

then the $90 \%$ is taken for the training and the last $10 \%$ is used for testing. With the same division (90-10\%) another $90 \%$ is selected for training and the other held-out $10 \%$ (different from the previous) is used for testing. This procedure is repeated ten times with different $90 \%$ selections. This approach helps for the estimation of the error with the first 10 runs and for the implementation of the classifier with the eleventh run. Once the cross validation was implemented, the software runs the algorithm with the whole data set for the eleventh time. This leads to the production of the classifier usable for the prediction of the analysed variable. The initial data set variables here considered for the regression is the following: electrode material (Mat), electrode nominal outer diameter (Dext), energy level (E), peak current (I), voltage (V), energy per spark $(\mathrm{E} / \mathrm{S})$, energy per second $(\mathrm{E} / \mathrm{s})$, total number of sparks (S), number of sparks per second $(\mathrm{S} / \mathrm{s})$. The regression equation, obtained using the linear approach and reporting only the significant parameters, is reported below:

$$
\text { wear }=0.9362 \cdot \operatorname{Mat}(\mathrm{Cu})-0.0084 \cdot D_{\text {ext }}+0.0023 \cdot E-0.034 \cdot I+2.3151
$$


The electrode wear model tree for non-linear approach is reported in Figure 9. Each branch of the model tree is constituted by a linear regression equation. It is possible to notice that the model considers only the electrode nominal diameter, the energy level and the electrode material, for the first level of the tree. Every branch of the tree is represented by a linear model (LM) as follows:

$$
\begin{aligned}
& \quad L M 1: w=1.1949 \cdot \operatorname{Mat}(\mathrm{Cu})-6 \cdot 10^{-4} \cdot D+2.2 \cdot 10^{-3} \cdot E+2.6 \cdot 10^{-3} \cdot I+1.247 \\
& \quad L M 2: w=0.072 \cdot \operatorname{Mat}(\mathrm{Cu})-6 \cdot 10^{-4} \cdot D+1.38 \cdot 10^{-2} \cdot I-3.1 \cdot 10^{-3} \cdot V-7 \cdot 10^{-4} \cdot \frac{E}{S}-10^{-4} \cdot S-1.22 \cdot \\
& 10^{-2} 0.0122 \cdot \frac{E}{S}+1.1491 \\
& L M 3: w=0.1689 \cdot \operatorname{Mat}(\mathrm{Cu})-6 \cdot 10^{-4} \cdot D+1.71 \cdot 10^{-2} \cdot I-0.0138 \cdot V-4 \cdot 10^{-4} \cdot \frac{E}{S}-10^{-4} \cdot S+2.3 \cdot 10^{-3} \cdot \frac{E}{S}+ \\
& 1.5034 \\
& L M 4: w=0.1689 \cdot \operatorname{Mat}(\mathrm{Cu})-6 \cdot 10^{-4} \cdot D+0.0364 \cdot I-5.4 \cdot 10^{-3} \cdot V-10^{-4} \cdot \frac{E}{S}-10^{-4} \cdot S+2.3 \cdot 10^{-3} \cdot \frac{E}{S}+
\end{aligned}
$$
1.3854

The same linear and non-linear regression approach was applied for the machining time. The linear equation is reported below: $t=506.6735 \cdot \operatorname{Mat}(T c)+1.7624 \cdot D_{\text {ext }}-1.3055 \cdot E+48.3054 \cdot I-13.8123 \cdot V-0.2715 \cdot S+251338$

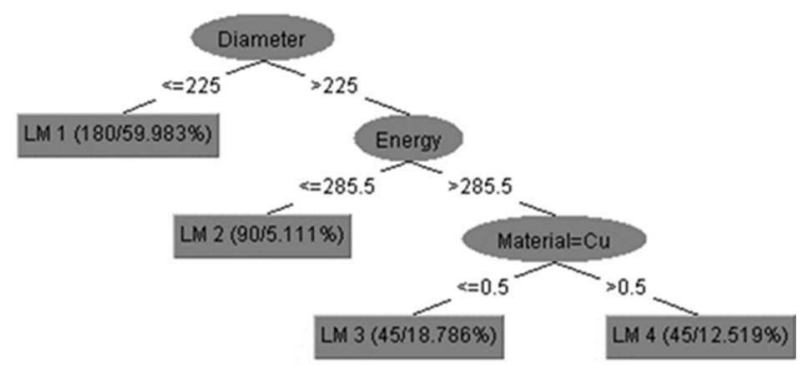

Fig. 9 Non-linear model tree approach for the electrode wear

A satisfactory correlation coefficient as regards the elctrode wear was obtained for the linear model (0.86) while the introduction of the model tree approach does not improve significantly the prediction capabilities (0.87), obtained in the face of greater complexity. As regards the machining time, the correlation coefficient for the linear model is lower $(0.79)$ if compared with the electrode wear one. Moreover, the regression tree provides only a slight improvement $(0.83)$ in the correlation coefficient and for this reason it is not reported. The regression models were also defined for the geometrical characteristics, obtaining satisfactory correlation coefficients. Within the limits of the present investigation the proposed models can be considered as a valid tool for the selection of process parameters as a function of the final output specifications.

\section{Conclusive remarks}

In the present paper the effects of the exchanged power and electrode properties, in terms of material and diameter, on the performance of micro EDM drilling of stainless steel were investigated. A suitable acquisition system for the measurement of effective electrical parameters during the drilling process was implemented and then the power discharged was calculated. A DOE approach was applied and ANOVA demonstrated that all the considered parameters influence the process. Both material and diameter electrode affect the discharged power; copper electrode, having a lower electrical resistivity, resulted in a higher exchanged power with respect to the tungsten carbide. For all the conditions (material and diameter electrode) MRR is directly proportional to the power discharged while the reduction of diameter electrode results in a lower MRR for both tungsten carbide and copper electrode. Copper permits to obtain higher removal speeds than tungsten carbide thanks to its electrical properties. Discharged power affects TWR in different way as a function of the electrode material: using tungsten carbide electrode, TWR has a decreasing trend as a function of the discharged power while, using copper electrode, the trend is opposite due to the higher electrical conductivity and lower melting point with respect to tungsten carbide. The reduction of the electrode diameter makes the process performance worse in terms of MRR and TWR. For DOC and TR no significant trends were found. Regarding the two electrode materials, copper permits to have holes with lower conicity than using tungsten carbide due to its higher erosion speed and to the resulting lower permanence time of the tool in the hole. The measurement of the actual process parameters and the application of machine learning techniques enabled the development of predictive models based on linear and non-linear regression approaches for the forecast process and product performance.

\section{References}

[1] TRYCH, A. (2013). Further Study of Carbon Fibers Electrodes in Micro Electrical Discharge Machining. In Procedia CIRP, Vol. 6, pp. 309-313.

[2] SUNDARAM, M. M., PAVALARAJAN, G.B., RAJURKAR, K. P.A (2008). Study on Process Parameters of Ultrasonic Assisted Micro EDM Based on Taguchi Method. In: JMEPEG, Vol. 17, pp. 210-215.

[3] WEUlE, H., FLEISCHER, J., BOOKHOLZ, C., KNOLL, M., ELSNER, J., TRITSCHLER, H. (2004). International state of the art of micro production technology. In: Prod Eng Res Dev, Vol. 11, pp. 29-36. 
[4] LI, J., YIN, G., WANG, C., GUO, X., YU, Z. (2013). Prediction of aspect ratio of a micro hole drilled by EDM. In: Journal of Mechanical Science \& Technology, Vol. 27, pp. 185-190.

[5] TONG, H., Li, Y., et al. (2013). Mechanism design and process control of micro EDM for drilling spray holes of diesel injector nozzles. In: Precision Engineering, Vol. 37, pp. 213-221.

[6] MAHDAVINEJAD, R.A., MAHDAVINEJAD, A. (2015) ED machining of WC-Co. In: Journal of Materials Processing Technology, Vol. 162163, pp. 637-643.

[7] ZHANG, Y., LIU, Y., SHEN, Y., JI, R., LI, Z., ZHENG, C. (2014). Investigation on the influence of the dielectrics on the material removal characteristics of EDM. In: Journal of Mat. Proc. Tech., Vol. 214, pp. 1052- 1061.

[8] JAHAN, M.P., WONG, Y.S., RAHMAN, M. (2009). A study on the quality micro-hole machining of tungsten carbide by micro-EDM process using transistor and RC-type pulse generator. In: Journal of Materials Processing Technology, Vol. 209, pp. 1706-1716.

[9] LEE, S.H., LI, X. (2003). Study of the surface integrity of the machined workpiece in the EDM of tungsten carbide. In: Journal of Materials Processing Technology, Vol. 139, pp. 315-321.

[10] MOURALOVA, K., KOVAR, J., KARPISEK, Z., KOUSA, P. (2016). Optimization Machining of Titanium Alloy Ti-6Al-4V by WEDM with Emphasis on the Quality of the Machined Surface. In: Manufacturing Technology, Vol. 16, No. 6, pp. 1326-1331.

[11] MOURALOVA, K., BENES, L., ZAHRADNICEK, R. (2017). Defects in the surface layer of pure molybdenum after WEDM. In: Manufacturing Technology, Vol. 17, No. 5, pp. 786-790.

[12] D’URSO, G., RAVASIO, C., MACCARINI, G. (2014). Process performance of micro-EDM drilling of stainless steel. In: Int $J$ Adv Manuf Technol., Vol. 72, pp. 1287-1298.

[13] PUERTAS, I., LUIS, C.J., ÁlVAREZ, L. (2004). Analysis of the influence of EDM parameters on surface quality, MRR and EW of WC-Co. In: Journal of Mat. Proc. Tech., Vol. 153-154, pp. 1026-1032.
[14] GOSTIMIROVIC, M., KOVAC, P., SKORIC, B., SEKULIC, M. (2012). Effect of electrical pulse parameters on the machining performance in EDM. In: Indian Journal of Engineering \& Material Sciences, Vol. 18, pp. 411-415.

[15] MUTHURAMALINGAM, T., MOHAN, B. (2015). A review on influence of electrical process parameters in EDM process. In: Archives of Civil and Mechanical Engineering, Vol. 15, pp. 87-94.

[16] HER, M.G.; WENG, F.T. (2001). Micro-hole Machining of Copper Using the Electro-discharge Machining Process with a Tungsten Carbide Electrode Compared with a Copper Electrode. In: International Journal of Advanced Manufacturing Technologies, Vol. 17, pp. 715-719.

[17] KHAN, A.A. (2009). Electrode wear and material removal rate during EDM of aluminium and mild steel using copper and brass electrodes. In: Int. J. Adv. Manuf. Tech., Vol. 39, pp. 482-487.

[18] JAHAN, M.P., WONG, Y.S., RAHMAN, M. (2009). A study on the fine-finish die-sinking micro-EDM of tungsten carbide using different electrode materials. In: J. Mat. Proc. Tech., Vol. 209, pp. 3956-3967.

[19] TSAI, H.C., YAN, B.H., HUANG, F.Y. (2003). EDM performance of $\mathrm{Cr} / \mathrm{Cu}$-based composite electrodes. In: International Journal of Machine Tools \& Manufacture, Vol. 43, pp. 245-252.

[20] LEE, H.T., HSU, F.C., TAI, T.Y. (2004). Study of surface integrity using the small area EDM process with a copper-tungsten electrode. In: Materials Science and Engineering, Vol. A364, pp. 346-356.

[21] MARAFONA, J.D., ARAUJO, A. (2009). Influence of workpiece hardness on EDM performance. In: International Journal of Machine Tools \& Manufacture, Vol. 49, pp. 744-748.

[22] LIU, H.S., TARNG, Y.S. (1997). Monitoring of the Electrical Discharge Machining Process by Abductive Networks. In: International Journal of Advanced Manufacturing Technologies, Vol. 13, pp. 264-270.

[23] D’URSO, G., QUARTO, M., PELlEGRINI G., RAVASIO, C. (2018). Towards the prediction of micro-EDM drilling performance on WC varying the hole depth. In: Manufacturing Technology, Vol. 18, No. 6, pp. 1041-1047. 